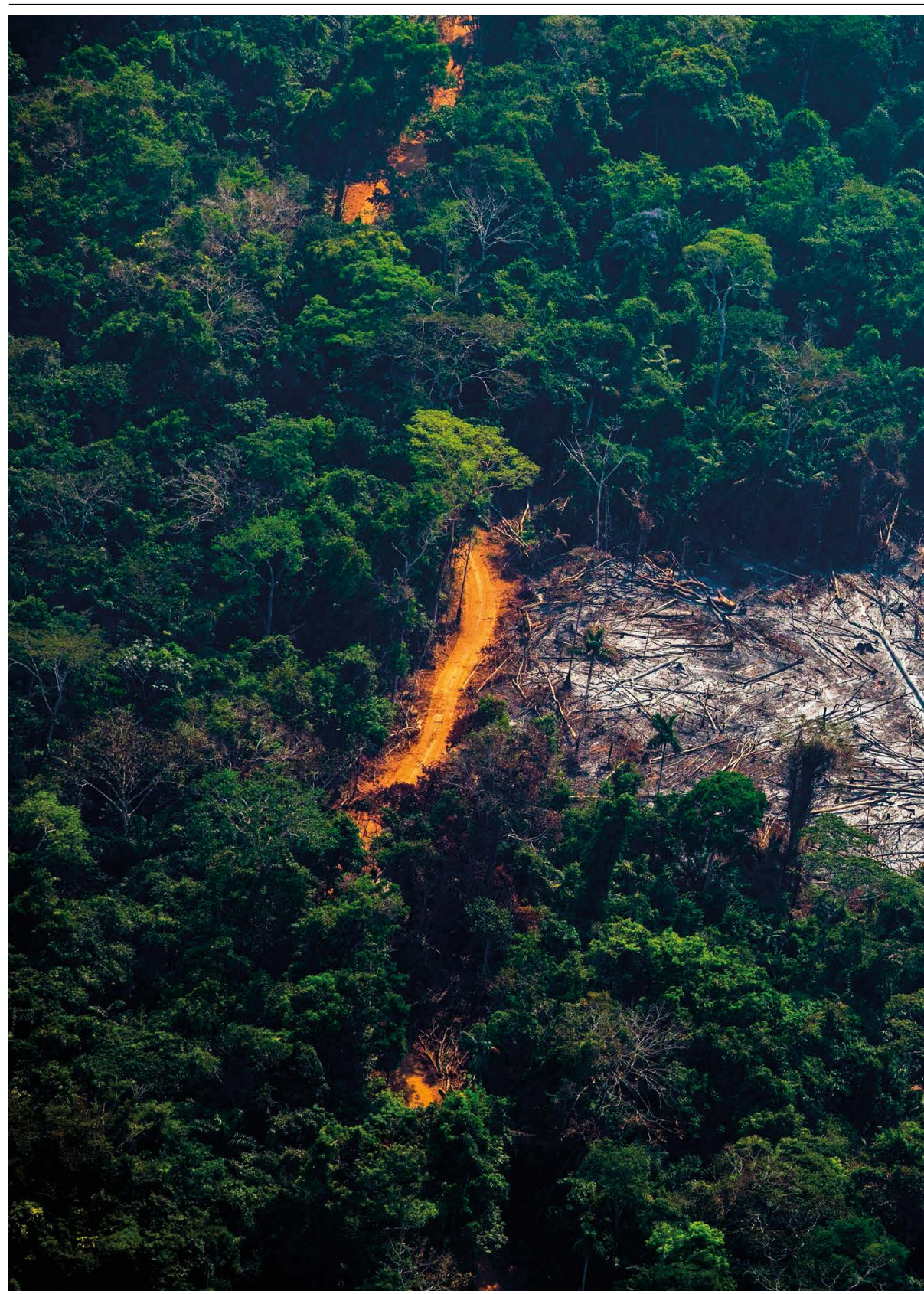

Deforestation in Altamira, Pará state, Brazil.

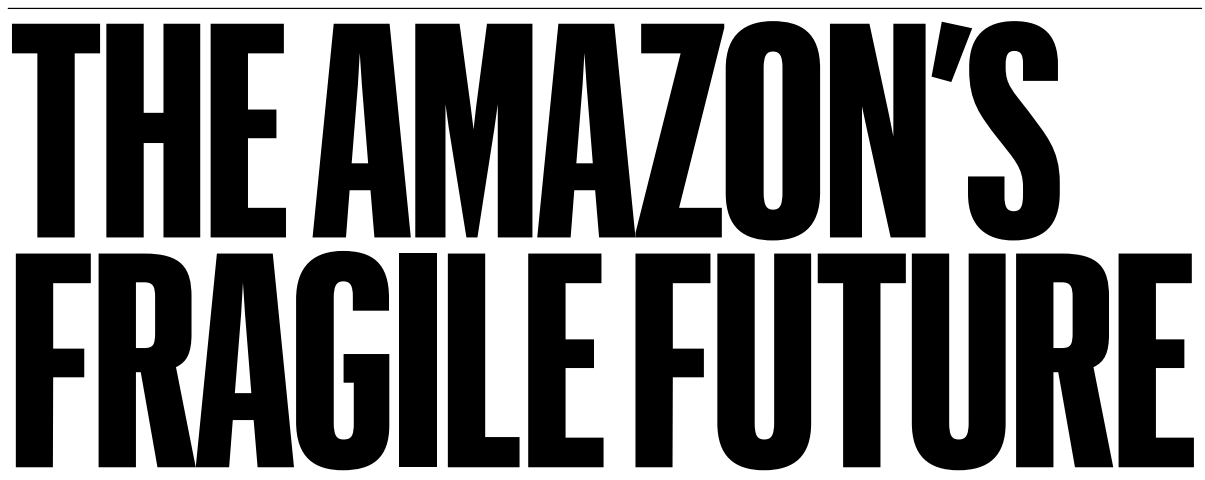

Scientists are trying to pin down how quickly climate change, deforestation and fires might ruin the world's largest tropical rainforest. By Ignacio Amigo

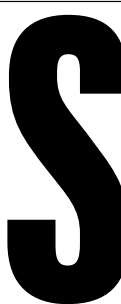

een from a monitoring tower above the treetops near Manaus in the Brazilian Amazon, the rainforest canopy stretches to the horizon as an endless sea of green. It looks like a rich and healthy ecosystem, but appearances are deceiving. This rainforest - which holds 16,000 separate tree species - is slowly drying out.

Over the past century, the average temperature in the forest has risen by $1-1.5^{\circ} \mathrm{C}$ (ref. 1 ). In some parts, the dry season has expanded during the past 50 years, from four months to almost five ${ }^{2}$. Severe droughts have hit three times since 2005. That's all driving a shift in vegetation. In 2018, a study reported that trees that do best in moist conditions, such as tropical legumes from the genus Inga, are dying. Those adapted to drier climes, such as the Brazil nut tree (Bertholletia excelsa) are thriving ${ }^{3}$.

At the same time, large parts of the Amazon, the world's largest rainforest, are being cut down and burnt. Tree clearing has already shrunk the forest by around 15\% from its 1970s extent of more than 6 million square kilometres; in Brazil, which contains more than half the forest, more than $19 \%$ has disappeared. In the 2000s, Brazil was praised for drastically slowing forest loss, but the rate has since risen as a result of political turmoil and an economic recession. Last year, deforestation in Brazil spiked by around 30\% to almost $10,000 \mathrm{~km}^{2}$, the largest loss in a decade. And last August, videos of wildfires in the Amazon made international headlines. The number of fires that month was the highest for any August since an extreme drought in 2010 (see 'Forest loss'). Many scientists have linked these surges to the anti-environmentalist rhetoric of Brazil's president, Jair Bolsonaro.

In the face of a warming climate, increased deforestation and fiercer fires, scientists are more worried than ever about the Amazon. Some have warned that the forest will soon reach a tipping point that could turn much of it into dry scrubland. But others say they lack the evidence to make specific forecasts about how long the rainforest can remain healthy.

Last September, a few dozen researchers formed a Science Panel for the Amazon that will report on the state of the rainforest, and suggest what needs to be done to conserve it. They hope to have their assessment ready in time for the United Nations climate negotiations in Glasgow, UK, this November.

There's little doubt that the situation is becoming dire. "It's a very difficult moment for those who know, love and work in Amazonia," says Eduardo Góes Neves, an archaeologist at the University of São Paulo, Brazil.

\section{The tipping-point question}

No matter the season, the temperature above the tree canopy is always high enough to make it sweaty for researchers climbing up a monitoring 


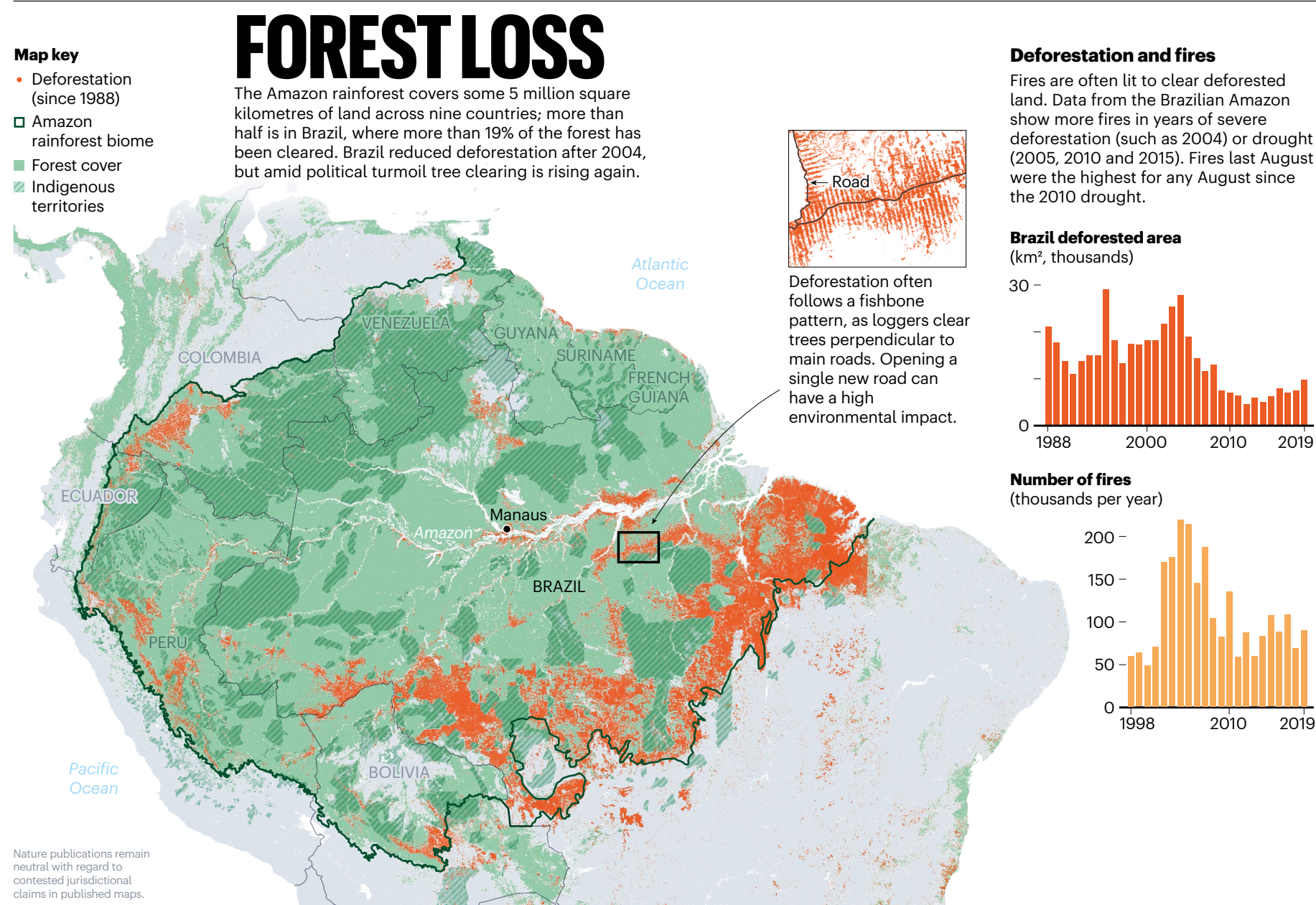

tower there. The air is full of moisture that sustains the rainforest ecosystem.

The forest plays a major part in keeping itself alive, by recycling water through trees to generate rainfall. A water molecule travelling across the Amazon can fall as rain up to six times ${ }^{4}$. If drought, fire or deforestation damage too many trees, reduced rainfall leads to less vegetation, and so on in a shrinking cycle. Eventually, this might transform large regions of the Amazon into an ecosystem more like a savannah (although with much less biodiversity). Only the western Amazon near the Andes mountains would remain lush - there, air currents are forced up over the mountains, causing water vapour to condense and fall as rain.

In 2018, Carlos Nobre, a climate researcher at the University of São Paulo, raised the alarm by arguing that the Amazon might be much closer to a tipping point than scientists thought. Heand Thomas Lovejoy, an environmental researcher at George Mason University in Fairfax, Virginia, wrote an editorial stating ${ }^{5}$ that if just 20-25\% of the rainforest were cut down, it could reach a tipping point at which eastern, southern and central Amazonia would flip to a savannah-like ecosystem. Last December the pair repeated the warning, calling it a last chance for action". "If the tree mortality we see continues for another 10-15years, then the southern Amazon will turn into a savannah," Nobre told Nature.
If that happens, it would not only affect the millions of people and animals in the region. It could also mean billions of tonnes of carbon dioxide will be emitted into the atmosphere as trees die and vegetation burns; less rainfall throughout central and southern South America; and altered climate patterns farther afield.

The pair's forecast was based in part, Nobre says, on 2016 simulations ${ }^{1}$ modelling how the forest of the 1970s (before deforestation accelerated) would look in 2050 under different scenarios. The researchers first modelled how the regional Amazonian climate might be affected using various projections about future climate change, levels of deforestation and increased fires. Then they simulated how the original rainforest would have evolved under these altered climate conditions. When they modelled 20\% forest loss with increased fires, more than half of the forest didn't survive by 2050. The modelling did not investigate how quickly the forest would die over the 80 years of the simulation.

Not everyone agrees on the $20 \%$ figure. Paulo Brando, a tropical ecologist at the University of California, Irvine, says it might require more deforestation to reach a critical point - but the main thing, he says, is to try to keep well away from it. "We're playing an environmental Russian roulette," he says.

And some other researchers aren't sure that it's even possible to define critical deforestation thresholds. "The jury's out on that," says Peter Cox, a climate researcher at the University of Exeter, UK, who was one of the first to study an Amazon tipping point in detail in the 2000s. "I don't think there is currently a strong scientific basis for defining precise thresholds of deforestation or global warming," he says. He adds that the idea could give the false impression that the Amazon is safe below a certain threshold of deforestation and doomed above it. Scientists agree, however, that more global warming and more deforestation put the rainforest at increased risk.

When the term was first introduced, a tipping point referred to an abrupt change of state: in the Amazon's case, when the rainforest biome becomes unstable and regions swiftly transform into dry scrubland. But some now use it more loosely, Cox says, to refer to conditions that seem to lead inevitably to large-scale and dangerous damage, even when there isn't an abrupt moment of change.

\section{Uncertain resilience}

Part of the problem is that a lack of data makes it hard to predict how climate change, deforestation and fires intersect, and how the forest will react. One big uncertainty is how a warmer climate enriched with $\mathrm{CO}_{2}$ would affect the Amazon. Extra $\mathrm{CO}_{2}$ could help the forest to flourish - but low levels of the nutrient 
phosphorus in the region's soil might limit plant growth, says Anja Rammig, an ecologist at the Technical University of Munich, Germany.

Rammig and others have for years been hoping to test the effect of elevated $\mathrm{CO}_{2}$ concentrations in the Amazon, by pumping the gas from towers into 30-metre-wide circular patches of forest and monitoring how this affects the ecosystem. Researchers have performed similar experiments - called free-air $\mathrm{CO}_{2}$ enrichment (FACE) - in other forests, but not in tropical ones. Several FACE trials have found that young forests do seem to grow faster in increased $\mathrm{CO}_{2}$, although mature eucalyptus trees did not gain extra biomass, a study in Australia reported ${ }^{7}$.

In 2013, researchers secured US $\$ 1.25$ million from the Inter-American Development Bank to kick-start the Amazon FACE project. But political and economic turmoil in Brazil from 2015 onwards meant that the study's funding was not renewed. Researchers collected baseline measurements on how plots of trees behaved, but haven't yet built towers to pump out $\mathrm{CO}_{2}$. For the moment, they are measuring the effect of high concentrations of $\mathrm{CO}_{2}$ on individual saplings.

“It's something novel, but it won't give us the answers at the ecosystem scale that we would get with a real FACE experiment," says David Lapola, a researcher at the University of Campinas, Brazil, and one of the leaders of the Amazon FACE team.

Another uncertainty is how to model fires. Most fires in the Amazon are intentional - set either by farmers to fertilize soil or by ranchers to clear deforested land for cattle. In wet years, the fires spread less easily, but in drier years, more trees die and flames surge higher, says Brando. Once a forest is hit by fire, patches become drier and thus more flammable: "The forest turns into a Swiss cheese, full of holes. And through these holes you get more wind and more sunlight," says Erika Berenguer, a tropical ecologist based jointly at the University of Oxford and Lancaster University, UK.

This January, Brando and others published a paper suggesting that a warmer, drier climate could double the area of burnt forest in the southern Brazilian Amazon over the next three decades ${ }^{8}$. Their study indicates that, even without deforestation, climate change alone will inevitably cause a surge in the area burnt over the coming years.

Researchers also need to improve their understanding of how hundreds of Amazon tree species react to heat and drought, says Oliver Phillips, a tropical ecologist at the University of Leeds, UK. That requires extensive laboratory and field testing, such as setting up a system that simulates a drought by capturing water droplets before they reach the soil. Studies have collected such data in forested areas of east Amazonia, but not in the hotter, drier southern Amazon, Phillips says.

But Bolsonaro is not supporting the science that might help to pin down answers about the Amazon's resilience. During his election campaign, he told the Brazilian Academy of Sciences that he thought it possible to boost investment in research from $1.3 \%$ to $3 \%$ of gross domestic product by the end of the forthcoming presidential term. But since his government took office, the scientific research budget, which had already shrunk heavily, has suffered extra cuts. Last year, Bolsonaro fired the director of the National Institute for Space Research, which is responsible for satellite monitoring in the Amazon. The president had denigrated the institute's reports of deforestation rates as lies. That left Brazilian researchers uneasy about publishing work that could upset the government. Last year, several scientists decided not to appear as authors on a study that discussed the causes of the August wildfires, saying they feared government retaliation.

\section{Regrowth needed}

The Amazon science panel hasn't yet drafted its report, but researchers have a good sense of what it is likely to recommend. The urgent priority is to halt deforestation. Another is to

\section{"The government has shown so far that it doesn't have any interest in preserving the Amazon."}

promote the growth of new forest in degraded areas. A 2016 study that analysed thousands of plots across 45 sites in South America showed that secondary forests that emerged in abandoned agricultural lands can take up huge amounts of carbon, at rates up to 11 times faster than those of old-growth forests 9 .

“There's a very high potential for restoration in the Amazon, especially in areas that have fairly recently been cleared or burnt and have not been used for agricultural production," says Robin Chazdon, an expert on tropical-forest restoration at the University of the Sunshine Coast in Sippy Downs, Australia.

In areas that have been heavily deforested, things are more complicated. A 2019 study showed that regrowth between 1999 and 2017 in an Amazon area that had been deforested several times over the past few decades happened slowly, and that the resulting forests accumulate less carbon and have lower biodiversity than native, primary forests ${ }^{10}$.

Under the 2015 Paris climate agreement, Brazil pledged to restore $120,000 \mathrm{~km}^{2}$ of forest by 2030 . In the longer term, Nobre thinks that Brazil needs to reforest even more - some $200,000 \mathrm{~km}^{2}$ - in southern and eastern Amazonia, the areas most heavily hit by deforestation.

Nobre and others have also put forward a plan to commercialize Amazonian products in a sustainable way. There is untapped potential in certain foods, they say - including the Brazil nut and fruits such as guarana and açai - which are already sold, but could be produced on an industrial scale. The plan includes restoring degraded areas through low-impact agriculture systems such as agroforestry, in which farmers grow food crops alongside trees and shrubs.

But Bolsonaro's policies are heading in a different direction. Last November, the government lifted a ten-year ban on planting sugar cane in the Amazon. And a bill to regulate mining and oil exploration in Indigenous lands will soon make its way to Brazil's national congress. If passed, it could threaten large swathes of well-conserved forest that are managed by Indigenous communities.

In January, the government announced the creation of an agency called the Amazon Council, which it said would "coordinate activities involving protection, defence and sustainable development in the Amazon". Many scientists are sceptical of the move. Paulo Artaxo, an atmospheric physicist at the University of São Paulo, says the council has been created just "to give the impression that something is being done". The government did not respond to Nature's request for comment.

The government would do better, Artaxo says, to reinstate operation of the Amazon Fund. Created in 2008 to support conservation and sustainable development, the fund had received payments worth almost $\$ 1.3$ billion from international donors, but a decree from Bolsonaro's government unilaterally restructured its funding mechanisms in April last year. Its main funders, Norway and Germany, promptly froze their new payments and accused Brazil of breaking the deal. "The government has shown so far that it doesn't have any interest in preserving the Amazon," says Artaxo.

And earlier this month, more than 1,000 scientists signed an open letter warning that "the administration of president Jair Bolsonaro is dismantling the country's socialenvironmental policies"11. "It's an emergency situation," says Adriane Esquivel Muelbert, an ecologist at the University of Birmingham, UK, and one of the letter's signatories. "We can fix this, but we need to act now."

Ignacio Amigo is a science writer based in Manaus, Brazil.

\footnotetext{
1. Nobre, C. A. et al. Proc. Natl. Acad. Sci. USA 113, 10759-10768 (2016).

2. Marengo, J. A. \& Espinoza, J. C. Int. J. Climat. 36 1033-1050 (2015).

3. Esquivel-Muelbert, A. et al. Glob. Change. Biol. 25 39-56 (2019).

4. Staal, A. et al. Nature Clim. Change 8, 539-543 (2018)

5. Lovejoy, T. E. \& Nobre, C. Sci. Adv. 4, eaat2340 (2018)

6. Lovejoy, T. E. \& Nobre, C. Sci. Adv. 5, eaba2949 (2019).

7. Jiang, M. et al. Preprint at bioRxiv https://doi. org/10.1101/696898 (2019).

8. Brando, P. M. et al. Sci. Adv. 6, eaay1632 (2020)

9. Poorter, L. et al. Nature 530, 211-214 (2016).

10. Elias, F. et al. Ecology https://doi.org/10.1002/ecy.2954 (2019)

11. Levis, C. et al. Nature Ecol. Evol. 4, 172-173 (2020).
} 